\title{
Cross-resistance profiles of malaria mosquito P450s associated with pyrethroid resistance against WHO insecticides
}

\author{
Cristina Yunta ${ }^{\text {a }}$, Kay Hemmings ${ }^{\text {a }}$, Bradley Stevenson ${ }^{\text {a }}$, Lizette L. Koekemoer ${ }^{\text {b }}$, Tonderi Matambo ${ }^{\text {, }}$,

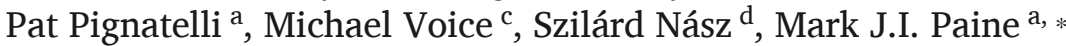 \\ ${ }^{a}$ Liverpool School of Tropical Medicine, Pembroke Place, Liverpool L3 5QA, UK

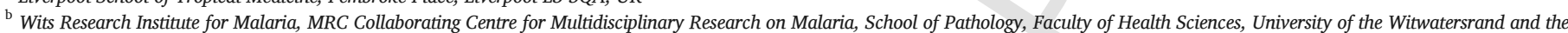 \\ Centre for Emerging, Zoonotic \& Parasitic Diseases, National Institute for Communicable Diseases, Johannesburg, South Africa \\ ${ }^{c}$ Cypex Ltd, Tom McDonald Avenue, Dundee DD2 1NH, UK \\ d Syngenta, Product Metabolism and Analytical Sciences, Jealott's Hill International Research Centre, Bracknell RG42 6EY, UK
}

\section{ARTICLE INFO}

Keywords:

P450

Insecticide resistance

Diagnostic

Metabolism

Mosquito

Malaria

\begin{abstract}
A B S T R A C T
Extensive use of pyrethroids for malaria control in Africa has led to widespread pyrethroid resistance in the two major African vectors of malaria An. gambiae and An. funestus. This is often associated with constitutively elevated levels of cytochrome P450s involved with pyrethroid metabolism and detoxification. P450s have the capacity to metabolise diverse substrates, which raises concerns about their potential to cause cross-resistance. A bank of seven recombinant P450s from An. gambiae (CYPs 6M2, 6P2, 6P3, 6P4, 6P5, 9J5) and An. funestus (CYP6P9a) commonly associated with pyrethroid resistance were screened against twelve insecticides representing the five major classes of insecticides recommended by WHO for malaria control; permethrin, etofenprox and bifenthrin (type I pyrethroids), deltamethrin, lambda cyhalothrin and cypermethrin (type II pyrethroids), DDT (organochlorine), bendiocarb (carbamate), malathion, pirimiphos methyl and fenitrothion (organophosphates) and pyriproxyfen (juvenile hormone analogue). DDT was not metabolised by the P450 panel, while bendiocarb was only metabolised by CYP6P3. Pyrethroids and pyriproxyfen were largely susceptible to metabolism by the P450 panel, as were organophosphates, which are activated by P450s. Primiphos-methyl is increasingly used for malaria control. Examination of the pirimiphos-methyl metabolites generated by CYP6P3 revealed both the active pirimiphos-methyl-oxon form and the inactive oxidative cleavage product 2-diethylamino-6-hydroxy-4-methylpyrimidine. The inhibition profile of CYPs 6M2, 6P2, 6P3, 6P9a and 9J5 was also examined using diethoxyfluorescein (DEF) as the probe substrate. Bendiocarb was the weakest inhibitor with $\mathrm{IC}_{50}>100 \mu \mathrm{M}$ across the P450 panel, while CYP6M2 showed strongest inhibition by malathion ( $\left.\mathrm{IC}_{50} 0.7 \mu \mathrm{M}\right)$. The results suggest that P450s present at elevated levels in two major Anopheline vectors of malaria in Africa have the capacity to metabolise a diverse range of pyrethroid and organophosphate insecticides as well as pyriproxyfen that could impact vector control.
\end{abstract}

\section{Introduction}

Cases of malaria transmitted by Anopheline mosquitoes in Africa have halved since the millennium due to the use of long-lasting insecticide treated bednets (LLINs) as well as indoor residual spraying (IRS) of houses and improved drug therapy (Bhatt et al., 2015). Since 2000 over a billion LLINS have been distributed across the continent, how- ever, with pyrethroids being the predominant insecticide class approved for use with LLINs, pyrethroid resistance is now widespread in $A n$. gambiae and An. funestus (J Hemingway et al., 2016a) the two major vectors of malaria. Two alternative classes of insecticide, organochlorines and carbamates, recommended for IRS by the World Health Organization are increasingly being used for IRS. However, mosquito populations are already showing resistance to these as well (Ranson and Lissenden, 2016), most notably in Cote d'Ivoire and Mali

Abbreviations: $\mathrm{b}_{5}$, cytochrome $b_{5}$; CPR, cytochrome P450 reductase; CYP, cytochrome P450; DEF, diethoxyfluorescein; IRS, indoor residual spray; LLIN, long-lasting insecticide treated bednets.

* Corresponding author.

Email address: mark.paine@1stmed.ac.uk (M.J.I. Paine) 
with resistance to all four classes (Cisse et al., 2015; Ranson et al., 2012). Pyriproxyfen, a juvenile hormone analogue, and chlorfenapyr, a pyrrole insecticide, are being trialled for use with bednets (Bayili et al., 2017; Tiono et al., 2015), while novel chemistries are due to enter the market in the next few years ( ). However, with resistance mechanisms in African mosquitoes primed by exposure to pyrethroids, early identification of potential cross-resistance issues is an important consideration in the delivery of insecticides for vector control.

A number of different mechanisms can lead to insecticide resistance including target site insensitivity, cuticular thickening, behavioural avoidance and biodegradation (Hemingway et al., 2004; Li et al., 2006; Wood et al., 2010). The latter is driven by the constitutive overexpression of detoxifying enzymes (metabolic resistance) and frequently associated with the overexpression of cytochrome P450 enzymes (CYPs) (David et al., 2013). In the past decade transcriptome studies have shown CYPs 6P3 and 6M2 to be commonly over expressed in pyrethroid resistant populations of An. gambiae (David et al., 2013; Paine and Brooke, 2016), while CYPs 6P9a, 6P9b and 6M7 in An. funestus are frequently associated with pyrethroid resistance (Coetzee and Koekemoer, 2013; Riveron et al., 2013; Wondji et al., 2009). Since P450s can metabolise structurally diverse substrates, populations of pyrethroid resistant mosquitoes with constitutively elevated P450 levels may have the capacity to metabolise other insecticide classes, potentially leading to cross-resistance. Indeed, CYP6P3 has been shown to metabolise bendiocarb (Edi et al., 2014) as well as pyriproxyfen (Yunta et al., 2016) along with six other P450s associated with pyrethroid resistance (CYPs 6M2, 6P2, 6P3, 6P4, 6P5 and 6Z2) (Yunta et al., 2016). This highlights the potential for pyrethroid metabolising P450s to impact vector control using other classes of insecticides. Conversely, elevated levels of P450 activity could promote negative cross-resistance in metabolically activated organophosphates such as malathion, fenitrothion and pirimiphos-methyl. This is particularly relevant for pirimiphos-methyl, which has been reformulated as Actellic ${ }^{\circledR} 300 \mathrm{CS}$ to increase longevity on sprayed walls (Kanyangarara et al., 2016; Oxborough et al., 2014; Rowland et al., 2013) and is now widely used for IRS operations to control pyrethroid resistant mosquito strains in Africa (Oxborough, 2016).

In vitro screening for drugs metabolised or inhibited by recombinant P450 enzymes is well established as a means of early identification of potential P450-mediated drug interactions in vivo (Wienkers and Heath, 2005). Here, we have established a bank of six recombinant P450s that have been found overexpressed in pyrethroid resistant populations of An. gambiae (CYPs 6M2, 6P2, 6P3, 6P4, 6P5, 9J5) and one that is fre- quently associated with pyrethroid resistance in An. funestus (CYP6P9a). They were used to examine the metabolism and inhibition of compounds representing five major classes of insecticides recommended by WHO for adult mosquito control (Fig. 1). The results provide a profile of P450-mediated insecticide interactions in vitro that may help inform the prediction of potential resistance liabilities in the field.

\section{Materials and methods}

\subsection{Reagents}

Oligonucleotides were synthesized by Eurofins genomics and enzymes for DNA manipulation were supplied by Thermo Scientific. Isopropyl-ß-D-thio-galactopyranoside (IPTG), 5-aminolevulinic acid (ALA), and 3-[(3-cholamidopropyl)-dimethylammonio]-1-propanesulfonate (CHAPS) were supplied by Melford (UK). Insecticides were supplied by ChemService: 1,1,1-trichloro-2,2-di(4-chlorophenyl)ethane (DDT), (S)- $\alpha$-cyano-3-phenoxybenzyl $\quad(1 R, 3 R)$-cis-2,2-dimethyl-3-(2,2-dibromovinyl)-cyclopropanecarboxylate (deltamethrin) and 3-phenoxybenzyl (1R,S)-cis,trans-3-(2,2-dichlorovinyl)-2,2-dimethylcyclopropanecarboxylate (permethrin, mixture of isomers). HPLC solvents were supplied by Fisher Scientific. Other chemicals were obtained from Sigma-Aldrich unless indicated otherwise.

\subsection{Gene cloning}

The pCWori + expression vector was used for the production of $A$. gambiae CYPs 6M2 and 6P3, 6P4, 6P5, 9J5 as previously described (Yunta et al., 2016). The cDNA sequence encoding CYP6P9a (GenBank ID: AY729661, previously named CYP6P9) was isolated by RT-PCR using RNA purified from An. funestus FUMOZ as described (Matambo et al., 2010). Our first attempt to express CYP6P9a used the E. coli ompA leader sequence and pCW-ori + as previously described for CYP6Z2 (Mclaughlin et al., 2008) were unsuccessful. Therefore we used another common strategy for P450 expression, which is to replace the natural P450 amino-terminus with a sequence (MALLLAVF) derived from the bovine steroid $17 \alpha$-hydroxylase (Barnes et al., 1991). To introduce the amino-terminal $17 \alpha$ modification the 5 '-end of CYP6P9a cDNA was amplified using KOD DNA polymerase (Novagen) with the forward primer: 5'-TTCATATGGCTCTGTTATTAGCAGTTTTTGCCGCGTTCATCTTCG-

TAG-3' (NdeI restriction site at the initiation codon, underlined), and the reverse primer $5^{\prime}$ - CGCTCTAGACTA-

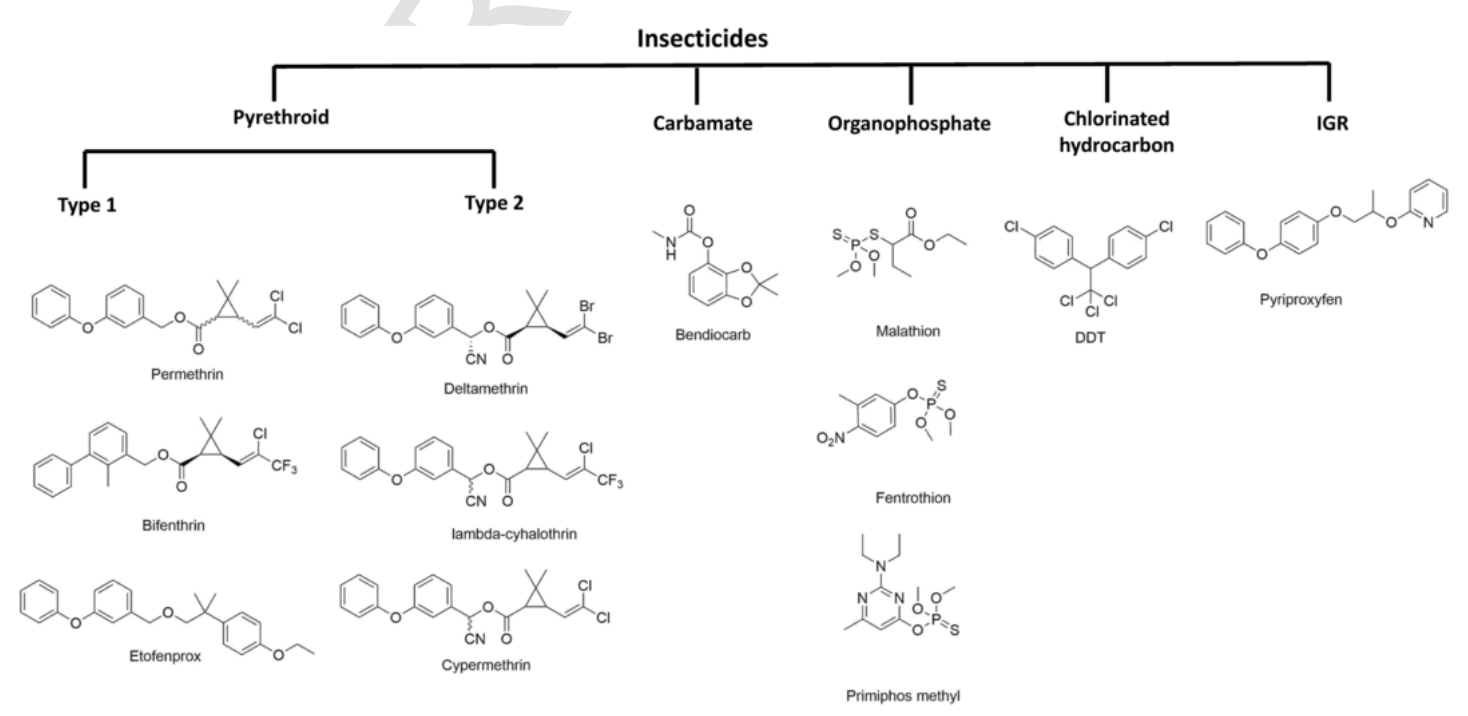

Fig. 1. Chemical structures of WHO insecticides used in this study. 
CAACTTTTCCACCTTC-3' (with an XbaI restriction site, underlined). The resulting $17 \alpha$-CYP6P9 was ligated into pCWmod1 via NdeI and XbaI to create $\mathrm{pCW}:: 17 \alpha$-CYP6P9a. The construct was sequenced and the amino acid sequence matches CYP6P9a (GenBank: ACG68818.1) (Wondji et al., 2009). A single plasmid expression system for the P450 and CPR was constructed by ligating the expression cassette (cDNA and tactac promotor) containing the An. gambiae NADPH P450 reductase (CPR) cDNA from the pACYC:AgCPR plasmid described above into the pCW:P450 expression plasmid. Briefly, the expression cassette containing the promoter and $\mathrm{Ag}$ CPR sequence was cut from a pCW based expression vector with BamHI and ligated into BamHI digested pCW::17 $\alpha$ - CYP6P9a. This yielded a plasmid with the Ag CPR and CYP6P9a expression cassettes in a 'head to tail' orientation with the CYP6P9a cassette following the Ag CPR cassette. In the new construct, although the expression of each of Ag CPR and CYP6P9a is under the control of its own promoter, the addition of IPTG to the culture induces the expression of both as the control in each case is a tactac promoter.

\subsection{Production of E. coli membranes co-expressing P450 and AgCPR}

CYPs 6M2, 6P3 and 6P9a were co-expressed with AgCPR from a single plasmid, while CYPs 6P4, 6P5, 9J5 were co-expressed with AgCPR following co-transformation of competent $E$. coli DH5 $\alpha$ cells with pCW:P450 plasmid and pACYC:AgCPR. Cultures were supplemented with $1.0 \mathrm{mM} 5$-aminolevulinic acid (heme precursor) and incubated at $23^{\circ} \mathrm{C}$ for $18-24 \mathrm{~h}$ after $1 \mathrm{mM}$ IPTG induction. P450 expression, E. coli membrane isolation and determination of P450 and AgCPR content was performed as previously described (Yunta et al., 2016). Samples were stored in aliquots at $-80^{\circ} \mathrm{C}$. An. gambiae cytochrome $b_{5}\left(\mathrm{~b}_{5}\right)$ was prepared as described previously to supplement enzyme reactions at a 10:1 M ratio, $b_{5}: P 450$ (Stevenson et al., 2011).

\subsection{Insecticide metabolism}

P450s were tested against the insecticides from the WHO recommended list of insecticides for public health use. Catalytic activity was assessed by measuring substrate turnover (disappearance of substrate with time). $10 \mathrm{mM}$ stock concentrations of insecticides were prepared in methanol or acetonitrile and diluted to $10 \times$ the assay concentration in $20 \%(v / v)$ methanol or acetonitrile immediately before each experiment to minimise precipitation of insecticide. Standard reactions contained a final organic solvent concentration of $2 \%(\mathrm{v} / \mathrm{v})$ with $20 \mu \mathrm{M}$ insecticide, $0.1 \mu \mathrm{M}$ P450, $1.0 \mu \mathrm{M}$ cyt b5 in $200 \mathrm{mM}$ Tris- $\mathrm{HCl}$ for $\mathrm{pH} 7.4$, and NADPH regeneration components ( $1 \mathrm{mM}$ glucose-6-phosphate (G6P), $0.25 \mathrm{mM}$ $\mathrm{MgCl}_{2}, 0.1 \mathrm{mM} \mathrm{NADP}{ }^{+}$, and $1 \mathrm{U} / \mathrm{mL}$ Glucose-6-phosphate dehydrogenase (G6PDH)). These were incubated for a specified time at $30^{\circ} \mathrm{C}$ with $1200 \mathrm{rpm}$ orbital shaking and quenched by adding $0.2 \mathrm{~mL}$ of acetonitrile or methanol. Samples were then incubated with shaking as before for an additional $10 \mathrm{~min}$ before centrifuging at $20,000 \times g$ for $5 \mathrm{~min} .0 .15 \mathrm{~mL}$ of the supernatant was then transferred to HPLC vials, stored at room temperature and analyzed within $24 \mathrm{~h}$. Reactions were performed in triplicate and compared against a negative control with no NADPH regenerating system to calculate substrate depletion.

\subsection{HPLC analysis}

$100 \mu \mathrm{L}$ of organic solvent-quenched reaction supernatant was analyzed by reverse-phase HPLC with a $250 \mathrm{~mm}$ C18 column (Acclaim 120, Thermo Scientific) and a mobile phase optimized for each insecticide (Table S1). The system was set at $23^{\circ} \mathrm{C}$ with $1 \mathrm{~mL} / \mathrm{min}$ flow rate except for bendiocarb it was performed at $40^{\circ} \mathrm{C}$. Reactions with permethrin, deltamethrin, etofenprox, bifenthrin or bendiocarb were monitored by absorbance at $226 \mathrm{~nm}$ whereas DDT, malathion, pyriproxyfen, pirimiphos-methyl and fenitrothion were monitored at $232 \mathrm{~nm}$. The insecticide was quantified by peak integration (OpenLAB Chromatography Data System). Elution times for all insecticides used are summarized in Table S1. In the case of stereoisomers in the insecticide mix, the insecticide concentrations were measured as the total area under the two peaks.

\subsection{Diethoxyfluorescein metabolism and $I C_{50}$ analysis}

Variable ligand concentrations were used for $\mathrm{IC}_{50}$ calculations with DEF used at $\sim \mathrm{K}_{\mathrm{M}}$ for each $\mathrm{P} 450$ (i.e. $0.5,1.4,0.7,1.0,3.5$ and $0.5 \mu \mathrm{M}$ for CYP6M2, CYP6P2, CYP6P3, CYP6P4 and CYP9J5 respectively) and $0.1 \mu \mathrm{M}$ P450. For calculation of the kinetic parameters $\left(\mathrm{K}_{\mathrm{M}}\right.$ and $\left.\mathrm{V}_{\max }\right)$, each P450 was used at a final concentration of $10 \mathrm{nM}$ ( $1 \mathrm{pmol} /$ reaction) and DEF concentrations in the range: $0,0.31,0.63,1.25,2.5,5,10$ and $20 \mu \mathrm{M}$. DEF reactions were carried out at $25^{\circ} \mathrm{C}$ in $50 \mathrm{mM} \mathrm{KPi}$ at $\mathrm{pH} 7.4$ containing $1 \mathrm{mM}$ glucose-6-phosphate (G6P), $0.1 \mathrm{mM} \mathrm{NADP}^{+}, 0.25 \mathrm{mM}$ $\mathrm{MgCl}_{2}$, and cytochrome $b_{5}$ at a 10:1 M ratio, $\mathrm{b}_{5}: \mathrm{P}_{450} \mathrm{NADP}^{+}$and G6P were excluded from the minus NADPH controls. For $\mathrm{IC}_{50}$ analysis, three replicates of positive and negative control reactions were run for each P450/substrate combination in opaque white 96-well (flat-based) plates in triplicate. The Michaelis-Menten and $\mathrm{IC}_{50}$ fitting calculations were performed using Graphpad Prism 6. Data were fitted to the dose-response model and plots with $\mathrm{R}^{2}<0.95$ were rejected.

\subsection{Mass spectrometry analysis for pirimiphos-methyl metabolism}

The chromatographic-mass spectrometric analysis was performed on a high resolution Thermo Q-Exactive mass spectrometer (MS) which was coupled to a 1290 series Agilent LC system. Separation of pirimiphos-methyl and its metabolites was carried out on a Waters Acquity BEH C18 $(2.1 \times 50 \mathrm{~mm} ; 1.7 \mu \mathrm{m})$ analytical column using water ( $0.1 \%$ formic acid) (A) and acetonitrile $(0.1 \%$ formic acid) (B) as mobile phases in a 12-min gradient program: $0-1 \mathrm{~min}(5 \% \mathrm{~B}) ; 1-8 \mathrm{~min}(5 \%$ B to $100 \% \mathrm{~B})$; $8-10 \mathrm{~min}(100 \% \mathrm{~B}) ; 10-10.1 \mathrm{~min}(100 \%$ B to $5 \% \mathrm{~B})$; $10.1-12 \min (5 \% \mathrm{~B})$. A sample volume of $5 \mathrm{ul}$ was injected. Throughout the chromatographic run time $(12 \mathrm{~min})$ a mass range of $100-1000 \mathrm{~m} / \mathrm{z}$ at $35 \mathrm{~K}$ resolution was monitored in full scan positive ion mode. The MS conditions for the analysis (heated electrospray capillary temperature, sheath gas, auxiliary gas flow rate, spray voltage) were constantly maintained at $320^{\circ} \mathrm{C}, 55$ (arbitrary units), 10 (arbitrary units), $3500 \mathrm{~V}$, respectively.

\section{Results}

\subsection{Profiling insecticide metabolism}

CYPs 6P2, 6P4, 6P5 and 9J5 were previously cloned into pCW-ori + and co-transformed with AgCPR-pACYC for small-scale (0.1-0.2L) E. coli expression (Yunta et al., 2016); co-expression of An. gambiae NADPH-cytochrome $\mathrm{P} 450$ oxidoreductase (AgCPR) being required for coupled electron transfer from NADPH to P450 for catalysis. CYPs 6M2, 6P3 and 6P9a were expressed in tandem with AgCPR from a single pCW-ori + plasmid to facilitate routine larger scale enzyme production (10-20 L fermentor); these P450s were amongst the earliest pyrethroid resistance markers to be functionally validated and most heavily used for in-vitro screening.. The relative P450 contents and CPR activities are provided in Table S2.

The catalytic activity of the P450s were assessed by measuring insecticide turnover against twelve WHO recommended insecticides in the presence and absence of NADPH. The insecticide classes and individual active ingredients tested included type I pyrethroids (permethrin, etofenprox and bifenthrin), type II pyrethroids (deltamethrin, 
lambda cyhalothrin and cypermethrin), an organochlorine (DDT), a carbamate (bendiocarb), organophosphates (malathion, pirimiphos methyl and fenitrothion) and a juvenile hormone analogue (pyriproxyfen). A cut-off value of $20 \%$ substrate depletion was used to distinguish true substrate turnover from baseline variability (Jones and Houston, 2004).

Results of pyrethroid metabolism are presented in Table 1. All pyrethroid compounds were metabolised to some degree by the P450 panel. Anopheles gambiae CYP6P3 produced $>75 \%$ substrate depletion for all pyrethroid substrates. Anopheles funestus CYP6P9a was similar, apart from lower levels of bifenthrin and lambda-cyhalothrin turnover (53.4 and $67.1 \%$ respectively). CYP6P4 demonstrated strong activity against deltamethrin, while CYPs 6P2, 6P5 and 9J5 produced lower, but reproducible deltamethrin turnover $(68.4,47.0$ and $58.1 \%$ respectively). Permethrin produced similar results except for CYP9J5, which displayed high activity comparable to CYP6P4. Etofenprox was strongly metabolised by all except for CYP6P5.

When tested against the other classes of insecticide (Table 2) none of the P450s showed significant activity against DDT (organochlorine) while only CYP6P3 metabolised bendiocarb (35\% substrate depletion). An. gambiae CYPs 6M2, 6P2, 6P3, 6P4, 6P5, and 9J5 have previously been shown to metabolise pyriproxyfen (Yunta et al., 2016). An. funestus CYP6P9a also metabolised the juvenile growth hormone ( $84.34 \pm 0.77 \%$ depletion) (Table 2). Except for CYP6M2 and pirimiphos-methyl $(8.5 \pm 1.4 \%$ depletion $)$ the three organophosphates malathion, pirimiphos-methyl and fenitrothion were metabolised by all the P450s tested.

Pirimiphos-methyl is becoming widely used for IRS operations. It requires $\mathrm{P} 450$ activation into the insecticidal pirimiphos-methyl oxon form to inhibit acetylcholinesterase, but can also undergo P450 medi- ated detoxifying dearylation reactions (Fig. 2). In order to investigate this further, LC-MS analysis was performed on the products of pirimiphos-methyl metabolism generated by An. gambiae CYP6P3 (Fig. 3), which represents one of the P450s most commonly overexpressed in pyrethroid resistant populations of An. gambiae (Ingham et al., 2018). Known metabolites 2-diethylamino-6-hydroxy-4-methylpyrimidine and its des-N-ethyl analogue, pirimiphos-methyl oxon and des-N-ethylpirimiphos-methyl were targeted using accurate mass technology (Roberts and Hutson, 1999). Extracted ion chromatograms of $[\mathrm{M}+\mathrm{H}]^{+}$indicated the presence of the insecticidal pirimiphos-methyl oxon $(\mathrm{m} / \mathrm{z}$ 290.1264) and the inactive 2-diethylamino-6-hydroxy-4-methylpyrimidine $(m / z 182.1287)$ although confirmation of metabolite identification for the latter was limited by a lack of analytical reference standards in our study (Fig. 3).

\subsection{Inhibition screening of WHO insecticide panel}

Fluorescent substrate based inhibition screening of P450s is routinely used in the pharmaceutical industry for investigating drug-drug interactions with P450s. As well as being a rapid method of screening for insecticide interactions with mosquito P450s, the relative strengths of inhibition of insecticides can indicate potential synergistic effects. The fluorogenic probe DEF was chosen as a general probe as it is metabolised by all of the P450s apart from CYP6P4 and CYP6P5. (Yunta et al., 2016). The ability of the panel of insecticides to inhibit the mosquito P450s was assayed and compared with piperonyl butoxide (PBO), a P450 inhibitor widely used in insecticide formulations as a synergist (Table 3). The compounds were categorized according to their activity as $\mathrm{P} 450$ inhibitors as potent $\left(\mathrm{IC}_{50}<1 \mu \mathrm{M}\right)$, moderate $\mathrm{IC}_{50}$ $1-10 \mu \mathrm{M})$ and weak inhibitors $\left(\mathrm{IC}_{50}>10 \mu \mathrm{M}\right)$ (Krippendorff et

Table 1

Pyrethroid metabolism by mosquito P450s.

\begin{tabular}{|c|c|c|c|c|c|c|}
\hline \multirow[t]{3}{*}{ P450 } & \multicolumn{6}{|c|}{$\%$ Insecticide depletion } \\
\hline & \multicolumn{3}{|c|}{ Pyrethroids type I } & \multicolumn{3}{|c|}{ Pyrethroids type II } \\
\hline & Permethrin & Etofenprox & Bifenthrin & Deltamethrin & $\lambda$-cyhalothrin & Cypermethrin \\
\hline \multicolumn{7}{|c|}{ Single plasmid } \\
\hline CYP6M2 $^{\mathrm{a}}$ & $58.5 \pm 2.2$ & $68.8 \pm 1.1$ & $38.9 \pm 1.6$ & $55.4 \pm 1.4$ & $49.4 \pm 0.5$ & $36.8 \pm 1.8$ \\
\hline $\mathrm{CYP} \mathrm{P}^{\mathrm{a}}$ & $100.0 \pm 0.0$ & $99.8 \pm 0.3$ & $76.7 \pm 0.3$ & $98.2 \pm 0.2$ & $83.3 \pm 15.4$ & $98.4 \pm 0.1$ \\
\hline CYP6P9a ${ }^{a}$ & $87.8 \pm 0.7$ & $98.5 \pm 0.2$ & $53.4 \pm 1.6$ & $97.0 \pm 0.2$ & $67.1 \pm 3.1$ & $89.5 \pm 2.7$ \\
\hline \multicolumn{7}{|l|}{ Dual plasmid } \\
\hline СYP6Р2 & $53.8 \pm 1.6$ & $75.5 \pm 4.2$ & nd & $68.4 \pm 4.8$ & nd & nd \\
\hline CYP6P4 & $88.5 \pm 0.4$ & $94.0 \pm 0.9$ & nd & $88.5 \pm 1.4$ & nd & nd \\
\hline CYP6P5 & $56.8 \pm 5.9$ & $24.4 \pm 5.5$ & nd & $47.0 \pm 1.9$ & nd & nd \\
\hline CYP9J5 & $76.9 \pm 1.2$ & $98.9 \pm 0.2$ & nd & $58.1 \pm 4.0$ & nd & nd \\
\hline
\end{tabular}

nd, not determined.

a Incubation time $2 \mathrm{~h}$ instead $90 \mathrm{~min}$.

Table 2

Non pyrethroid metabolism by P450s.

\begin{tabular}{|c|c|c|c|c|c|c|}
\hline \multirow[t]{2}{*}{ P450 } & \multicolumn{6}{|c|}{$\%$ Insecticide depletion } \\
\hline & DDT & Bendiocarb & Malathion & Pirimiphos-methyl & Fenithrothion & Pyriproxyfen \\
\hline \multicolumn{7}{|c|}{ Single plasmid } \\
\hline CYP6M2 & $2.9 \pm 2.1$ & $0 \pm 11.2$ & $26.8 \pm 8.8$ & $8.5 \pm 1.4$ & $35.4 \pm 10.4$ & $30.93 \pm 4.7^{*}$ \\
\hline CYP6Р3 & $4.1 \pm 5.6$ & $35.0 \pm 2.5$ & $68.8 \pm 8.4$ & $100.0 \pm 0.0$ & $58.2 \pm 11.7$ & $100.0 \pm 0.0^{*}$ \\
\hline СYP6Р9a & $3.9 \pm 2.3$ & $10.7 \pm 23.7$ & $31.0 \pm 4.1$ & $42.0 \pm 7.0$ & $41.9 \pm 10.3$ & $84.34 \pm 0.77$ \\
\hline \multicolumn{7}{|c|}{ Dual plasmid } \\
\hline CYP6P2 & $5.1 \pm 3.7$ & $5.2 \pm 1.6$ & $30.3 \pm 9.7$ & $50.6 \pm 10.1$ & $21.9 \pm 9.7$ & $58.03 \pm 1.4^{*}$ \\
\hline CYP6P4 & $1.4 \pm 1.5$ & $6.8 \pm 4.2$ & $44.4 \pm 10.1$ & $47.0 \pm 16.2$ & $42.8 \pm 14.9$ & $81.63 \pm 0.6 *$ \\
\hline CYP6P5 & $0.6 \pm 0.3$ & $7.9 \pm 2.9$ & $24.2 \pm 3.6$ & $23.6 \pm 7.5$ & $33.1 \pm 12.1$ & $39.96 \pm 1.0 *$ \\
\hline CYP9J5 & $2.6 \pm 2.5$ & $8.1 \pm 1.4$ & $66.7 \pm 9.2$ & $95.7 \pm 2.5$ & $50.7 \pm 6.5$ & $24.78 \pm 2.1^{*}$ \\
\hline
\end{tabular}

a Published in Yunta et al. (2016). 
<smiles>CCN(CC)c1nc(C)cc(OP(=S)(OC)OC)n1</smiles><smiles>CCN(CC)c1nc(C)cc(OP2(OC)(OC)OSC2(O)O)n1</smiles><smiles>CCN(CC)c1nc(C)cc(OP(=O)(OC)OC)n1</smiles>

\section{oxidative cleavage of the leaving group}

PMM-M3<smiles>CCN(CC)c1nc(C)cc(O)n1</smiles>

P450<smiles>COP(O)(=S)OC</smiles>

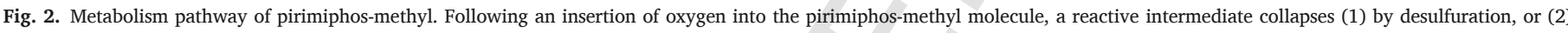

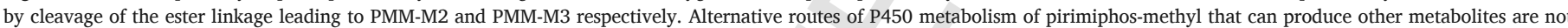

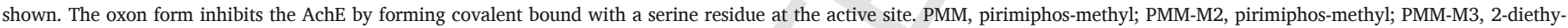
lamino-6-hydroxyl-4-methylpyrimidine and AchE, acetilholinesterase.

CYP6P3 + NADPH

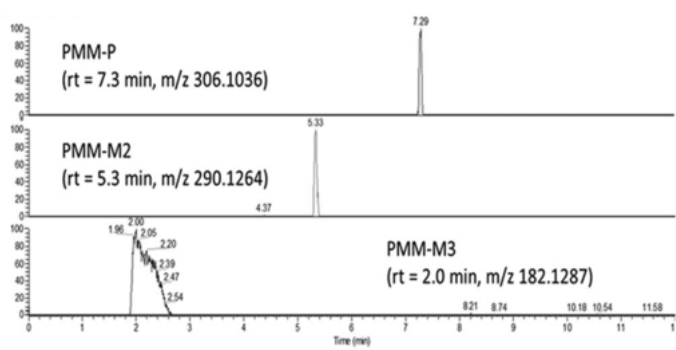

CYP6P3 - NADPH

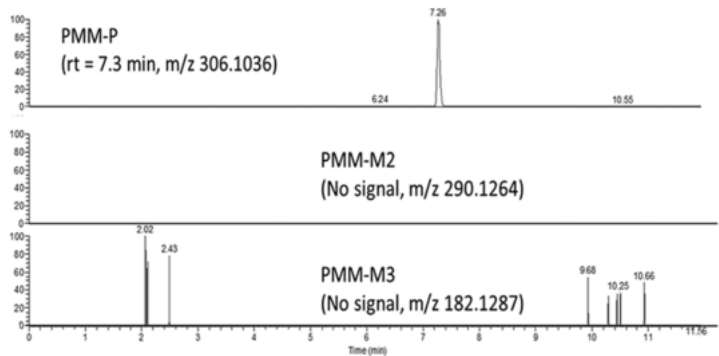

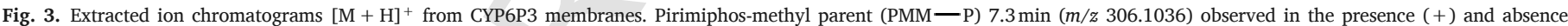

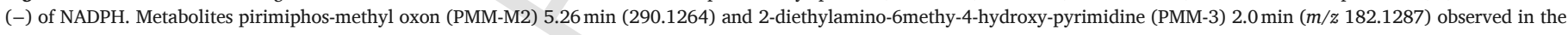
presence of NADPH. Signals within the extracted ion chromatograms at different retention times correspond to low level background ions and/or electronic spikes.

al., 2007). PBO was the strongest inhibitor with $\mathrm{IC}_{50}$ values ranging from $0.3 \mu \mathrm{M}$ with CYP6M2 to $3.9 \mu \mathrm{M}$ for CYP9J5. Pyrethroids and DDT were moderate to weak inhibitors in the range $3-17 \mu \mathrm{M}$. The inhibition profile of OP insecticides varied from potent inhibition of CYP6M2 by malathion $\left(\mathrm{IC}_{50}=0.7 \mu \mathrm{M}\right)$ to weak inhibition by fenitrothion of CYP9J5 $\left(\mathrm{IC}_{50}=48.9 \mu \mathrm{M}\right)$. Bendiocarb was the weakest inhibitor producing $\mathrm{IC}_{50}$ values in the range 100 to $>1000 \mu \mathrm{M}$.

\section{Discussion}

P450s play a key role in the metabolism and disposition of insecticides in mosquito vectors of malaria. Since P450s are capable of metabolising structurally diverse substrates, P450 mediated cross resistance between insecticide classes is a major concern (Edi et al., 2014). Having recently demonstrated that six An. gambiae P450s (CYPs 6M2, $6 \mathrm{P} 2,6 \mathrm{P} 3,6 \mathrm{P} 4,6 \mathrm{P} 5$, and 9J5) associated with pyrethroid resistance can metabolise pyriproxyfen (Yunta et al., 2016), we have further examined their ability to metabolise a wider range of insecticides represent- ing five major classes of insecticide recommended by WHO for vector control. We have also extended the panel of recombinant enzymes to include CYP6P9a from An. funestus (Matambo et al., 2010; Riveron et al., 2013; Wondji et al., 2009). Overall, there was limited activity against DDT and carbamate compounds but extensive enzyme cross-reactivity against all the pyrethroid and organophosphate compounds tested and the juvenile hormone inhibitor pyriproxyfen (Yunta et al., 2016).

Deltamethrin and permethrin are the most commonly used pyrethroids for LLINs. Both were metabolised by An gambiae CYP6M2, CYP6P3, and An funestus CYP6P9a, consistent with a role in detoxification as previously reported (Muller et al., 2008; Riveron et al., 2013; Stevenson et al., 2011). Furthermore, these P450s were also capable of metabolising etofenprox, bifenthrin $\lambda$-cyhalothrin and cypermethrin to varying degrees. The orthologues An. gambiae CYP6P3 and An. funestus CYP6P9a, produced particularly high levels of depletion across the pyrethroid range, with lowest substrate depletion levels observed for bifenthrin (77 and 53\% respectively), although this may be explained 
Table 3

$\mathrm{IC}_{50}$ values $(\mu \mathrm{M})$ of WHO insecticides.

\begin{tabular}{llllll}
\hline Insecticide & \multicolumn{2}{l}{ IC $_{50}$ values $(\mu \mathrm{M})$} & & & \\
& CYP6M2 & CYP6P3 & CYP6P9a & CYP6P2 & CYP9J5 \\
\hline Deltamethrin & $4.2^{\mathrm{a}}$ & $3.2^{\mathrm{a}}$ & 2.6 & $5.0^{\mathrm{a}}$ & $6.1^{\mathrm{a}}$ \\
Permethrin & $8.1^{\mathrm{a}}$ & $6.8^{\mathrm{a}}$ & 5.7 & $8.6^{\mathrm{a}}$ & $6.5^{\mathrm{a}}$ \\
$\lambda$-Cyhalothrin & 6.6 & 9.6 & 3.7 & 4.8 & 4.2 \\
Cypermethrin & 1.5 & 2.6 & 4.2 & 9.8 & 13.5 \\
Bifenthrin & 5.6 & 3.5 & 8.5 & 10.7 & 2.5 \\
Etofenprox & 12.0 & 8.3 & 8.1 & 4.7 & 8.0 \\
Pirimiphos & 4.3 & 3.0 & 1.7 & 14.9 & 5.3 \\
Malathion & 0.7 & 8.0 & 1.9 & 17.6 & 26.9 \\
Bendiocarb & $>1000$ & 185.2 & 102.9 & $>1000$ & $>1000$ \\
DTT & 8.7 & 3.1 & 3.1 & 13.4 & 13.3 \\
Fenitrothion & 11.5 & 22.5 & 13.0 & 26.7 & 48.9 \\
PBO & 0.3 & 2.0 & 1.2 & 2.7 & 3.9 \\
Pyriproxyfen & $14.1^{\mathrm{a}}$ & $15.8^{\mathrm{a}}$ & 9.9 & $9.9^{\mathrm{a}}$ & $19.9^{\mathrm{a}}$ \\
\hline
\end{tabular}

a Published in Yunta et al. (2016).

by the high levels of CPR contained in these membranes. A further four An gambiae P450s that are overexpressed in pyrethroid resistant populations (CYP6P2, CYP6P4, CYP6P5 and CYP9J5) (Edi et al., 2014; Hemingway et al., 2013; Toé et al., 2015) were confirmed to metabolise deltamethrin, permethrin and etofenprox, with highest levels of activity observed with An. gambiae CYP6P4 and CYP9J5. An. arabiensis CYP6P4 has previously been reported to selectively metabolise permethrin but not deltamethrin (Ibrahim et al., 2016). Since An. gambiae and An. arabiensis CYP6P4 are identical in amino acid sequence, differences in substrate metabolism might reflect different cytochrome $b 5$ ratios used and/or reaction times as we used a high P450: b5 ratio (1:10), and an extended reaction time $(90 \mathrm{~min})$. Bifenthrin and $\lambda$-cyhalothrin tended to produce lower turnover values. Both are fluorinated molecules, which limits sites of P450 metabolism, while bifenthrin is structurally constrained by a rigid bi-phenyl alcohol moiety that might limit binding in a catalytically productive orientation in the $\mathrm{P} 450$ active site.

The metabolism of the non-pyrethroid insecticides was varied. None of the P450s metabolised DDT, while CYP6P3 was the only P450 to metabolise bendiocarb, as previously demonstrated (Edi et al., 2014). Most striking was the broad cross-reactivity with organophosphate molecules. Pirimiphos-methyl, which is becoming widely used for IRS for malaria control in Africa (Oxborough, 2016), was highly metabolised by An. gambiae CYP6P3 (100\% depletion) and CYP9J5 (96\% depletion) as well as An. funestus CYP6P9a (42\% depletion). Mass spectrometry analysis of the products of CYP6P3 metabolism indicated that both the active pirimiphos-methyl-oxon form may be formed along with the inactive oxidative cleavage product 2-diethylamino-6-hydroxy-4-methylpyrimidine. Thus, elevated levels of expression of CYP6P3 and other cross-reacting P450s could feasibly increase or decrease pirimiphos-methyl insecticidal activity depending on the relative rates of production of the active pirimiphos-methyl-oxon and inactive oxidative cleavage products. At present, it is unclear if CYP6P3 is a positive marker for enhanced pirimiphos-methyl activity and mosquito susceptibility or if it is linked with resistance. This recommends further investigations to characterize the pharmacokinetic profile of pirimiphos-methyl metabolism in relation to mosquito control. It is notable that pyrethroid resistant populations of An. gambiae in western Kenya remain susceptible to an organophosphate (malathion) (Wanjala et al., 2015), while pirimiphos-methyl (Actellic ${ }^{\circledR} 300 \mathrm{CS}$ ) is effective against pyrethroid resistant Anopheles populations (Kanyangarara et al., 2016; Rowland et al., 2013). Conversely, resistance to pyrethroids and pirimiphos-methyl, as well as bendiocarb and DDT, has recently been de- tected in Anopheline mosquito populations in Tanzania (Kisinza et al., 2017).

While pyrethroid based LLINs have been integral to malaria control operations in Africa, the rapid increase in pyrethroid resistance is driving the use of alternative vector control strategies. This includes combining active ingredients with different modes of action. Pirimiphos-methyl for example is used for IRS alongside deltamethrin and permethrin impregnated nets (Oxborough, 2016), while new generation LLINs have been developed that incorporate both permethrin and pyriproxyfen (Tiono et al., 2018). The majority of the pyrethroid compounds produced moderate inhibition across the P450 range (IC50's $1-10 \mu \mathrm{M})$, suggesting that pyrethroid-P450 interactions could affect other active-ingredient biotransformation and potency that merits further research.

\section{Conclusions}

Overall, the in vitro profiling indicates that several Anopheles P450s associated with elevated levels of pyrethroid metabolism in African mosquito populations can metabolise at least 4 different insecticide classes recommended by WHO for malaria control. However, complex pharmacokinetic factors need to be taken into consideration and further research is recommended to identify the factors that influence insecticide metabolism and disposition in vivo. Nevertheless, with new active ingredients being developed for mosquito control in Africa $(\mathrm{J}$ Hemingway et al., 2016a), rapid in vitro profiling could be usefully applied to flag potential metabolic cross resistance liabilities. Furthermore, it would be advisable to continue to expand the bank of P450s to include other metabolic resistance candidates including CYP9K1, a P450 that is evolving strong association with deltamethrin resistance in An. coluzzii populations in Bioko Island, Equatorial Guinea (Vontas et al., 2018), An gambiae and An. coluzzii in Cameroon (Fossog Tene et al., 2013) and An. parensis in Uganda (Mulamba et al., 2014).

\section{Funding}

The research leading to these results has received funding from the European Union Seventh Framework Programme FP7 (2007-2013) under grant agreement no 265660 AvecNet.

\section{Uncited references}

Hemingway et al., 2016b

\section{Acknowledgements}

We are grateful to Kevan Richardson (Syngenta) and Dr. Hanafy Ismail (LSTM) for helpful comments in reviewing the manuscript and production of Figs. 1 and 3.

\section{Appendix A. Supplementary data}

Supplementary data to this article can be found online at https:// doi.org/10.1016/j.pestbp.2019.06.007.

\section{References}

Barnes, H.J., Arlotto, M.P., Waterman, M.R., 1991. Expression and enzymatic activity of recombinant cytochrome P450 17 alpha-hydroxylase in Escherichia coli. Proc. Natl. Acad. Sci. U. S. A. 88, 5597-5601. https://doi.org/10.1073/pnas.88.13.5597.

Bayili, K., N'do, S., Namountougou, M., Sanou, R., Ouattara, A., Dabiré, R.K., Ouédraogo, A.G., Malone, D., Diabaté, A., 2017. Evaluation of efficacy of Interceptor ${ }^{\circledR}$ G2, a long-lasting insecticide net coated with a mixture of chlorfenapyr and alpha-cypermethrin, against pyrethroid resistant Anopheles gambiae s.l. in Burkina Faso. Malar. J. 16, 190https://doi.org/10.1186/s12936-017-1846-4. 
Bhatt, S., Weiss, D.J., Cameron, E., Bisanzio, D., Mappin, B., Dalrymple, U., Battle, K.E., Moyes, C.L., Henry, A., Penny, M.A., Smith, T.A., Bennett, A., Yukich, J., Eisele, T.P., Eckhoff, P.A., Wenger, E.A., Brie, O., Griffin, J.T., Fergus, C.A., Lynch, M., Lindgren, F., Cohen, J.M., Murray, C.L.J., Smith, D.L., Hay, S.I., Cibulskis, R.E., Gething, P.W., 2015. The effect of malaria control on Plasmodium falciparum in Africa between 2000 and 2015. Nature 526, 1-9. https://doi.org/10.1038/nature15535.

Cisse, M.B.M., Keita, C., Dicko, A., Dengela, D., Coleman, J., Lucas, B., Mihigo, J., Sadou, A., Belemvire, A., George, K., Fornadel, C., Beach, R., 2015. Characterizing the insecticide resistance of Anopheles gambiae in Mali. Malar. J. 14, 327https://doi.org/10. 1186/s12936-015-0847-4.

Coetzee, M., Koekemoer, L.L., 2013. Molecular systematics and insecticide resistance in the major African malaria vector Anopheles funestus. Annu. Rev. Entomol. 58, 393-412. https://doi.org/10.1146/annurev-ento-120811-153628.

David, J.P., Ismail, H.M., Chandor-Proust, A., Paine, M.J., 2013. Role of cytochrome P450s in insecticide resistance: impact on the control of mosquito-borne diseases and use of insecticides on earth. Philos. Trans. R. Soc. L. B. Biol. Sci. 368, 20120429https://doi. org/10.1098/rstb.2012.0429.

Edi, C.V., Djogbénou, L., Jenkins, A.M., Regna, K., Muskavitch, M.A.T., Poupardin, R., Jones, C.M., Essandoh, J., Kétoh, G.K., Paine, M.J.I., Koudou, B.G., Donnelly, M.J., Ranson, H., Weetman, D., 2014. CYP6 P450 enzymes and ACE-1 duplication produce extreme and multiple insecticide resistance in the malaria mosquito Anopheles gambiae. PLoS Genet. 10, e1004236https://doi.org/10.1371/journal.pgen.1004236.

Fossog Tene, B., Poupardin, R., Costantini, C., Awono-Ambene, P., Wondji, C.S., Ranson, H., Antonio-Nkondjio, C., 2013. Resistance to DDT in an urban setting: common mechanisms implicated in both $\mathrm{M}$ and $\mathrm{S}$ forms of Anopheles gambiae in the City of Yaoundé Cameroon. PLoS One https://doi.org/10.1371/journal.pone.0061408.

Hemingway, J., Hawkes, N.J., McCarroll, L., Ranson, H., 2004. The molecular basis of insecticide resistance in mosquitoes. Insect Biochem. Mol. Biol. 34, 653-665. https:// doi.org/10.1016/j.ibmb.2004.03.018.

Hemingway, J., Vontas, J., Poupardin, R., Raman, J., Lines, J., Schwabe, C., Matias, A., Kleinschmidt, I., 2013. Country-level operational implementation of the global plan for insecticide resistance management. Proc. Natl. Acad. Sci. U. S. A. 110, 9397-9402. https://doi.org/10.1073/pnas.1307656110.

Hemingway, J., Ranson, H., Magill, A., Kolaczinski, J., Fornadel, C., Gimnig, J., 2016. Averting a malaria disaster: will insecticide resistance derail malaria control?. Lancet 387, https://doi.org/10.1016/S0140-6736(15)00417-1.

Hemingway, J., Shretta, R., Wells, T.N.C., Bell, D., Djimdé, A.A., Achee, N., Qi, G., 2016. Tools and strategies for malaria control and elimination: what do we need to achieve a grand convergence in malaria?. PLoS Biol. 14, e1002380https://doi.org/10.1371/ journal.pbio. 1002380

Ibrahim, S.S., Riveron, J.M., Stott, R., Irving, H., Wondji, C.S., 2016. The cytochrome P450 CYP6P4 is responsible for the high pyrethroid resistance in knockdown resistance-free Anopheles arabiensis. Insect Biochem. Mol. Biol. 68, 23-32. https://doi.org/10.1016/ j.ibmb.2015.10.015

Ingham, V.A., Wagstaff, S., Ranson, H., 2018. Transcriptomic meta-signatures identified in Anopheles gambiae populations reveal previously undetected insecticide resistance mechanisms. Nat. Commun. 9, 5282https://doi.org/10.1038/s41467-018-07615-x.

Jones, H.M., Houston, J.B., 2004. Substrate depletion approach for determining in vitro metabolic clearance: time dependencies in hepatocyte and microsomal incubations. Drug Metab. Dispos. 32, 973-982. https://doi.org/10.1124/dmd.104.000125.

Kanyangarara, M., Mamini, E., Mharakurwa, S., Munyati, S., Gwanzura, L., Kobayashi, T., Shields, T., Mullany, L.C., Mutambu, S., Mason, P.R., Curriero, F.C., Moss, W.J., 2016. Reduction in malaria incidence following indoor residual spraying with Actellic 300 CS in a setting with pyrethroid resistance: Mutasa District, Zimbabwe. PLoS One 11, e0151971https://doi.org/10.1371/journal.pone.0151971.

Kisinza, W.N., Nkya, T.E., Kabula, B., Overgaard, H.J., Massue, D.J., Mageni, Z., Greer, G., Kaspar, N., Mohamed, M., Reithinger, R., Moore, S., Lorenz, L.M., Magesa, S., 2017. Multiple insecticide resistance in Anopheles gambiae from Tanzania: a major concern for malaria vector control. Malar. J. 1-10. https://doi.org/10.1186/s12936-0172087-2.

Krippendorff, B.-F., Lienau, P., Reichel, A., Huisinga, W., 2007. Optimizing classification of drug-drug interaction potential for CYP450 isoenzyme inhibition assays in early drug discovery. J. Biomol. Screen. 12, 92-99. https://doi.org/10.1177/ 1087057106295897.

Li, X., Schuler, M.A., Berenbaum, M.R., 2006. Molecular mechanisms of metabolic resistance to synthetic and natural xenobiotics. Annu. Rev. Entomol. 52, 231-253. https: //doi.org/10.1146/annurev.ento.51.110104.151104.

Matambo, T.S., Paine, M.J.I., Coetzee, M., Koekemoer, L.L., 2010. Sequence characterization of cytochrome P450 CYP6P9 in pyrethroid resistant and susceptible Anopheles funestus (Diptera: Culicidae). Genet. Mol. Res. 9, 554-564. https://doi.org/10.4238/ Vol9-1gmr719.

Mclaughlin, L.A., Niazi, U., Bibby, J., David, J.P., Vontas, J., Hemingway, J., Ranson, H., Sutcliffe, M.J., Paine, M.J.I., 2008. Characterization of inhibitors and substrates of Anopheles gambiae CYP6Z2. Insect Mol. Biol. 17, 125-135. https://doi.org/10.1111/ j.1365-2583.2007.00788.x.

Mulamba, C., Irving, H., Riveron, J.M., Mukwaya, L.G., Birungi, J., Wondji, C.S., 2014. Contrasting Plasmodium infection rates and insecticide susceptibility profiles between the sympatric sibling species Anopheles parensis and Anopheles funestus s.s: A potential challenge for malaria vector control in Uganda. Parasit. Vectors https://doi.org/ 10.1186/1756-3305-7-71

Muller, P., Warr, E., Stevenson, B.J.J., Pignatelli, P.M.M., Morgan, J.C.C., Steven, A. Yawson, A.E.E., Mitchell, S.N.N., Ranson, H., Hemingway, J., Paine, M.J.I.J.I., Donnelly, M.J.J., 2008. Field-caught permethrin-resistant Anopheles gambiae overexpress CYP6P3, a P450 that metabolises pyrethroids. PLoS Genet. 4, ARTN e1000286. 10.1371/journal.pgen.1000286.

Oxborough, R.M., 2016. Trends in US President's Malaria initiative-funded indoor residual spray coverage and insecticide choice in sub-Saharan Africa (2008-2015): urgent need for affordable, long-lasting insecticides. Malar. J. 15, 1-9. https://doi.org/10.1186/ s12936-016-1201-1.

Oxborough, R.M., Kitau, J., Jones, R., Feston, E., Matowo, J., Mosha, F.W., Rowland, M.W., 2014. Long-lasting control of Anopheles arabiensis by a single spray application of micro-encapsulated pirimiphos-methyl (Actellic ${ }^{\circledR} 300$ CS). Malar. J. 13, 37https:// doi.org/10.1186/1475-2875-13-37.

Paine, M.J.I., Brooke, B., 2016. Insecticide resistance and its impact on control. In Horowitz, R.A., Ishaaya, I. (Eds.), Advances in Insect Control and Resistance Management. Springer, pp. 287-312. https://doi.org/10.1007/978-3-319-31800-4.

Ranson, H., Lissenden, N., 2016. Insecticide resistance in African Anopheles mosquitoes: a worsening situation that needs urgent action to maintain malaria control. Trends Parasitol. 32, 187-196. https://doi.org/10.1016/j.pt.2015.11.010.

Ranson, H., Edi, C.V.A., Koudou, B.G., Jones, C.M., Weetman, D., 2012. Multiple-insecticide resistance in Anopheles gambiae mosquitoes, southern côte d'ivoire. Emerg. Infect. Dis. 18, 1508-1511. https://doi.org/10.3201/eid1809.120262.

Riveron, J.M., Irving, H., Ndula, M., Barnes, K.G., Ibrahim, S.S., Paine, M.J.I., Wondji, C.S., 2013. Directionally selected cytochrome P450 alleles are driving the spread of pyrethroid resistance in the major malaria vector Anopheles funestus. Proc. Natl. Acad. Sci. U. S. A. 110, 252-257. https://doi.org/10.1073/pnas.1216705110.

Rowland, M., Boko, P., Odjo, A., Asidi, A., Akogbeto, M., N'Guessan, R., 2013. A new long-lasting indoor residual formulation of the organophosphate insecticide pirimiphos methyl for prolonged control of pyrethroid-resistant mosquitoes: an experimental hut trial in Benin. PLoS One 8, https://doi.org/10.1371/journal.pone.0069516.

Stevenson, B.J., Bibby, J., Pignatelli, P., Muangnoicharoen, S., O'Neill, P.M., Lian, L.Y., Muller, P., Nikou, D., Steven, A., Hemingway, J., Sutcliffe, M.J., Paine, M.J.I., 2011. Cytochrome P450 6M2 from the malaria vector Anopheles gambiae metabolizes pyrethroids: sequential metabolism of deltamethrin revealed. Insect Biochem. Mol Biol. 41, 492-502. https://doi.org/10.1016/j.ibmb.2011.02.003.

Stevenson, B.J., Pignatelli, P., Nikou, D., Paine, M.J.I., 2012. Pinpointing P450s associated with pyrethroid metabolism in the dengue vector, Aedes aegypti: developing new tools to combat insecticide resistance. PLoS Negl. Trop. Dis. 6, https://doi.org/10. 1371/Journal.Pntd.0001595, Artn E1595.

Tiono, A.B., Pinder, M., N'Fale, S., Faragher, B., Smith, T., Silkey, M., Ranson, H., Lindsay, S.W., 2015. The AvecNet Trial to assess whether addition of pyriproxyfen, an in sect juvenile hormone mimic, to long-lasting insecticidal mosquito nets provides additional protection against clinical malaria over current best practice in an area with pyrethroid-resist. Trials 16, 1-12. https://doi.org/10.1186/s13063-015-0606-4.

Tiono, A.B., Ouédraogo, A., Ouattara, D., Bougouma, E.C., Coulibaly, S., Diarra, A., Faragher, B., Guelbeogo, M.W., Grisales, N., Ouédraogo, I.N., Ouédraogo, Z.A., Pinder, M., Sanon, S., Smith, T., Vanobberghen, F., Sagnon, N., Ranson, H., Lindsay, S.W., 2018. Efficacy of Olyset Duo, a bednet containing pyriproxyfen and permethrin, versus a permethrin-only net against clinical malaria in an area with highly pyrethroid-resistant vectors in rural Burkina Faso: a cluster-randomised controlled trial. Lancet 0, https://doi.org/10.1016/S0140-6736(18)31711-2

Toé, K.H., N'Falé, S., Dabiré, R.K., Ranson, H., Jones, C.M., 2015. The recent escalation in strength of pyrethroid resistance in Anopheles coluzzi in West Africa is linked to increased expression of multiple gene families. BMC Genomics 16, 1-11. https://doi org/10.1186/s12864-015-1342-6.

Vontas, J., Grigoraki, L., Morgan, J., Tsakireli, D., Fuseini, G., Segura, L., Niemczura de Carvalho, J., Nguema, R., Weetman, D., Slotman, M.A., Hemingway, J., 2018. Rapid selection of a pyrethroid metabolic enzyme CYP9K1 by operational malaria control activities. Proc. Natl. Acad. Sci. https://doi.org/10.1073/pnas.1719663115.

Wanjala, C.L., Mbugi, J.P., Ototo, E., Gesuge, M., Afrane, Y.A., Atieli, H.E., Zhou, G., Githeko, A.K., Yan, G., 2015. Pyrethroid and DDT resistance and organophosphate susceptibility among anopheles spp. mosquitoes, western Kenya. Emerg. Infect. Dis. 21, 2178-2181. https://doi.org/10.3201/eid2112.150814.

Wienkers, L.C., Heath, T.G., 2005. Predicting in vivo drug interactions from in vitro drug discovery data. Nat. Rev. Drug Discov. 4, 825-833. https://doi.org/10.1038/nrd1851.

Wondji, C.S., Irving, H., Morgan, J., Lobo, N.F., Collins, F.H., Hunt, R.H., Coetzee, M., Hemingway, J., Ranson, H., 2009. Two duplicated P450 genes are associated with pyrethroid resistance in Anopheles funestus, a major malaria vector. Genome Res. 19, 452-459. https://doi.org/10.1101/gr.087916.108.

Wood, O.R., Hanrahan, S., Coetzee, M., Koekemoer, L.L., Brooke, B.D., 2010. Cuticle thickening associated with pyrethroid resistance in the major malaria vector Anopheles funestus. Parasit. Vectors 3, 67. https://doi.org/10.1186/1756-3305-3-67.

Yunta, C., Grisales, N., Nász, S., Hemmings, K., Pignatelli, P., Voice, M., Ranson, H., Paine, M.J.I., 2016. Pyriproxyfen is metabolized by P450s associated with pyrethroid resistance in An. gambiae. Insect Biochem. Mol. Biol. 78, 50-57. https://doi.org/10.1016/ j.ibmb.2016.09.001. 